Año 13.

Revista de Investigación

Núm. 33

Académica sin Frontera

ISSN: 2007-8870

http://revistainvestigacionacademicasinfrontera.com

Recibido el 30 de octubre de 2020. Dictaminado mediante arbitraje favorablemente 10 de diciembre de 2020.

\title{
LIMITACIÓN FISCAL EN LA DEDUCCIÓN DE GASTOS E INVERSIONES PARA SECTOR PRIMARIO
}

\author{
M. en I. Héctor Cecilio Meza Gaxiola \\ Universidad de Sonora \\ https://orcid.org/0000-0002-1593-6843 \\ cpc.hector_meza@hotmail.com \\ Dr. Fernando Calles Montijo \\ Universidad de Sonora \\ https://orcid.org/0000-0001-7544-2012 \\ fernando.calles@unison.mx \\ Dr. Sergio Félix Enríquez \\ Universidad de Sonora \\ https://orcid.org/0000-0002-4345-6089 \\ sergio.felix@unison.mx
}

\section{Resumen}

El presente artículo tiene como finalidad ofrecer un panorama sobre la opción que tienen los contribuyentes del sector primario acerca de la aplicación de la deducibilidad de los gastos e inversiones no deducibles en la proporción que representen los ingresos exentos respecto del total de ingresos. Afectando a dicho sector de contribuyentes en la limitación de la deducción de sus gastos e inversiones, generando también un Impuesto al Valor Agregado no deducible, no acreditable. Como se ve en esta investigación la razón principal de que esta fracción afecte al sector primario, es la contenida en la aplicación de la exención del Impuesto Sobre la Renta a ingresos gravados, contenida en el artículo 74 en sus diversos párrafos aplicables a personas físicas y morales respectivamente. Con la aplicación de los casos de estudio, se obtuvo como resultado general, la no conveniencia de la aplicación de la exención del artículo 74 por la implicación fiscal de la fracción II del artículo 28 para personas morales y un resultado 
Año 13.

Núm. 33

Académica sin Frontera

ISSN: 2007-8870

\title{
http://revistainvestigacionacademicasinfrontera.com
}

Recibido el 30 de octubre de 2020. Dictaminado mediante arbitraje favorablemente 10 de diciembre de 2020.

positivo en personas físicas. Por lo tanto, se recomienda a los contribuyentes, el analizar a fondo los beneficios fiscales antes de su aplicación

Palabras claves: Actividades Primarias, Deducción de Gastos e Inversiones.

\begin{abstract}
The purpose of this article is to offer an overview of the option that primary sector taxpayers have regarding the application of the deductibility of non-deductible expenses and investments in the proportion that exempt income represents with respect to total income. Affecting said sector of taxpayers in the limitation of the deduction of their expenses and investments, also generating a non-deductible, non-creditable Value Added Tax. As seen in this investigation, the main reason that this fraction affects the primary sector is the one contained in the application of the Income Tax exemption to taxed income, contained in Article 74 in its various paragraphs applicable to individuals and morals respectively. With the application of the case studies, it was obtained as a general result, the non-advisability of applying the exemption of article 74 due to the fiscal implication of section II of article 28 for legal entities and a positive result in individuals. Therefore, taxpayers are recommended to thoroughly analyze the tax benefits before their application.
\end{abstract}

Keywords: Primary Activities, Expense and Investment depreciation

\section{Introducción}

En la actualidad la economía del país no es la mejor de los últimos años, lo anterior se ejemplifica con ciertos elementos tales como el aumento de la gasolina, la devaluación del peso frente al dólar y el aumento del índice de pobreza del país. Motivo por el cual los empresarios del país buscan ser más eficiente en sus recursos y aplicarlos de la mejor manera. Un aspecto que resulta particularmente importante es lo referente al pago de contribuciones 
Año 13.

Núm. 33

Académica sin Frontera

ISSN: 2007-8870

\section{http://revistainvestigacionacademicasinfrontera.com}

Recibido el 30 de octubre de 2020. Dictaminado mediante arbitraje favorablemente 10 de diciembre de 2020.

a las que se está obligado, para que les quede un poco más del esfuerzo de su trabajo; esto debe ser de una forma legal, sin caer en algún tipo de defraudación fiscal. No hay que olvidar que todas las personas físicas y morales están obligadas a contribuir para el gasto público, tal como lo establece la Constitución Política de los Estados Unidos Mexicanos en el artículo 31 fracción IV.

En la presente Investigación, se analizará las actividades primarias, diferenciadas por la ley del Impuesto Sobre la Renta (LISR) en el régimen especial denominado como: Régimen de actividades Agrícolas, Ganaderas, Silvícolas y Pesqueras.

El gobierno considera a este sector de la población económico empresarial muy importante para el desarrollo del país, por varias razones. Primeramente, trata de incentivar para que se produzca el alimento que consume el país, por otro lado, se le considera como un sector vulnerable el cual no cuenta con el conocimiento requerido para contribuir de igual forma que otras actividades. Por estas y otras razones, el sector en contexto se hace acreedor de varios beneficios tributarios algunos de ellos son: facilidades administrativas, exenciones y reducciones en Impuestos, además un régimen fiscal preferente, entre otros.

\section{Material y Método}

Las actividades primarias, en lo particular sobre la aplicación de exención de I.S.R. representa un estímulo fiscal bastante favorecedor, que aplicándolo a personas morales que las conformen 10 socios, no pagaría el Impuesto Sobre Renta hasta por un monto en sus Ingresos de hasta \$6׳342,240.00 en el ejercicio 2020, de ser el caso de tener mayores ingresos, por ellos sí tendría que pagar I.S.R., por lo cual, después de revisar en diversas fuentes de información, y tomando como ejemplo el libro “Actividades Agropecuarias 2019” de L.C. Antonio Luna Guerra, "Sector Primario Régimen Fiscal Agricultura, Ganadería, 
Año 13.

Núm. 33

Académica sin Frontera

ISSN: 2007-8870

\section{http://revistainvestigacionacademicasinfrontera.com}

Recibido el 30 de octubre de 2020. Dictaminado mediante arbitraje favorablemente 10 de diciembre de 2020.

Silvicultora y Pesca" de José Pérez Chávez y Raymundo Fol Olguín, páginas web de fiscalistas como contadormx.com, kimquezada.com, entre otras fuentes y también conocer diversas empresas agrícolas; se llega a la conclusión de que al momento de que se calcula el Impuesto Sobre la Renta (ISR) de personas físicas y morales con actividades primarias, dichos autores limitan la deducción de gastos e inversiones por aplicar una exención sobre ingresos, con fundamento en el Artículo 28 de la Ley del Impuesto Sobre la Renta (LISR) Fracción II, que limita las deducciones en gastos e inversiones proporcionalmente al total de sus ingresos sobre sus ingresos exentos.

Lo anteriormente señalado tiene algunas consecuencias como, por ejemplo, se ven limitados en la deducción de gastos e inversiones, generando erogaciones no deducibles para el Impuesto Sobre la Renta y un Impuesto al Valor Agregado no deducible, no acreditable y por lo tanto no se podría solicitar su devolución. Es por esto que bastantes contribuyentes de este sector optan por no aplicar esta exención, siendo necesario tomar en cuenta varios factores donde implique el cálculo de Impuestos con la aplicación de dicha exención y sin ella, para llegar a una benéfica decisión para el contribuyente.

En la actualidad existe la opción de renunciar a la exención mediante la regla 3.3.1.24 de la Miscelánea Fiscal para 2020 se da la opción de poder acreditar el I.V.A sobre los gastos e inversiones exentos, siempre y cuando se rechace la opción de aplicar la exención en Impuestos contenida en la L.I.S.R. y aceptando las consecuencias de no aplicar dicha exención.

Las empresas con actividades Agrícolas, Ganaderas, Silvícolas y Pesqueras, por el solo hecho de que las leyes fiscales como L.I.S.R. o como el Código Fiscal de la Federación (CFF) las considere como actividades primarias, se hacen acreedoras a varios beneficios 
Año 13.

Núm. 33

Académica sin Frontera

ISSN: 2007-8870

\section{http://revistainvestigacionacademicasinfrontera.com}

Recibido el 30 de octubre de 2020. Dictaminado mediante arbitraje favorablemente 10 de diciembre de 2020.

tributarios entre los más comunes están; facilidades administrativas publicadas en el diario oficial de la federación, exenciones sobre ingresos afectos para el Impuesto Sobre la Renta; así como también reducciones, estímulos fiscales contenidos en la Ley de Ingresos de la federación, estímulos fiscales contenidos en la ley de ingresos del estado de Sonora, decreto por el cual se otorga reducción en pago de cuotas obrero patronal, entre otras.

Por lo que es de gran importancia investigar si este sector de la economía nacional aprovecha eficientemente dichos beneficios, siendo el presente caso de estudio las implicaciones fiscales de la deducción de gastos e inversiones de manera proporcional a sus ingresos gravados según lo previsto en el artículo 28 fracción segunda de la L.I.S.R. Dado a que, dicho numeral es aplicable al sector primario, siempre y cuando se aplique el beneficio fiscal contenido en el artículo 74 párrafo 11 que presenta la exención del Impuesto sobre la renta sobre ingresos gravados, que en persona moral para el año 2020 puede llegar a ser de hasta \$ 6’342,240.00 siendo un beneficio bastante positivo para este sector.

Como se menciona en el párrafo anterior en la LISR en su capítulo VIII del título II hace mención al régimen de Actividades Agrícolas, Ganaderas, Silvícolas y Pesqueras (Actividades Primarias); en el cual, se describe la exención sobre Ingresos gravados, prevista en el Artículo 74 párrafo 11, surgiendo la necesidad de indagar sobre los efectos de la aplicación sobre dicha exención y las repercusiones que afectan en la deducción de gastos e inversiones para el sector.

Los ingresos gravados se convierten en ingresos exentos al aplicar la exención del artículo 74 anteriormente señalado. Es decir, expone una exención sobre ingresos, bastante atractiva a primera instancia; la cual el contribuyente puede llegar aplicar sin realizar ningún tipo de comparación de conveniencia, lo cual puede resultar perjudicial. Es por esto, que 


\section{http://revistainvestigacionacademicasinfrontera.com}

Recibido el 30 de octubre de 2020. Dictaminado mediante arbitraje favorablemente 10 de diciembre de 2020.

surge la necesidad de conocer a más a profundidad sobre la aplicación o no de dicha exención y de sus consecuencias; con la finalidad principal de evaluar si es benéfica para el contribuyente la aplicación de la exención o es más conveniente el rechazarla.

Motivos por los que se desarrollara los pros y contras que de esta aplicación emanan, con la finalidad de verificar que este sector de la población aproveche de la mejor manera sus beneficios tributarios. Ya que como es conocido, existen personas afectas a este sector que renuncian a dicha exención, apegados a la regla 3.3.1.24 de la Miscelánea Fiscal para 2020 la cual indica que siempre y cuando acumulen los ingresos exentos que emanan de la exención prevista del artículo 74, el sector primario podrá deducir los gastos e inversiones; sin aplicar la proporción del artículo 28 fracción II, con la finalidad de no limitar sus gastos e inversiones, entre otras consecuencias necesarias de identificar y concientizar.

Como, por ejemplo, el generar un Impuesto al Valor Agregado no deducible, el cual fue efectivamente pagado por el contribuyente y cumplió con cada uno de los requisitos de deducibilidad que en la L.I.S.R. se enlistan. Para valorar las consecuencias positivas o negativas, anteriormente descritas es necesario llevar a cabo la presente investigación de la cual se obtendrá un dictamen de lo más conveniente para el sector, a través del conocimiento fiscal necesario, principalmente de las diferentes formas de tributación, los elementos para realizar un cálculo veraz del impuesto sobre la renta y por consiguiente realizar de manera práctica ejercicios, que nos arrojará un resultado obligatorio para fundamentar una opinión y por lo tanto una recomendación certera. 
Año 13.

Revista de Investigación

Núm. 33

Académica sin Frontera

ISSN: 2007-8870

\section{http://revistainvestigacionacademicasinfrontera.com}

Recibido el 30 de octubre de 2020. Dictaminado mediante arbitraje favorablemente 10 de diciembre de 2020.

\section{Actividades primarias.}

Las actividades primarias comprenden todas las actividades que se basan en la extracción de bienes y recursos procedentes del medio natural: agricultura, ganadería, pesca, caza, explotación forestal y minería. (UNICEF, 2010).

Las actividades primarias, comprendidas por las actividades agrícolas, ganaderas silvícolas y pesqueras, sujetas al régimen fiscal incluido en el Capítulo VIII de la LISR denominado como régimen de actividades agrícolas, ganaderas, silvícolas y pesqueras. Se definen según el Código Fiscal de la Federación en el artículo 16 en sus particulares fracciones de la siguiente manera:

1. Las agrícolas que comprenden las actividades de siembra, cultivo, cosecha y la primera enajenación de los productos obtenidos, que no hayan sido objeto de transformación industrial.

2. Las ganaderas que son las consistentes en la cría y engorda de ganado, aves de corral y animales, así como la primera enajenación de sus productos, que no hayan sido objeto de transformación industrial.

3. Las de pesca que incluyen la cría, cultivo, fomento y cuidado de la reproducción de toda clase de especies marinas y de agua dulce, incluida la acuacultura, así como la captura y extracción de las mismas y la primera enajenación de esos productos, que no hayan sido objeto de transformación industrial.

4. Las silvícolas que son las de cultivo de los bosques o montes, así como la cría, conservación, restauración, fomento y aprovechamiento de la vegetación de los 


\section{http://revistainvestigacionacademicasinfrontera.com}

Recibido el 30 de octubre de 2020. Dictaminado mediante arbitraje favorablemente 10 de diciembre de 2020.

mismos y la primera enajenación de sus productos, que no hayan sido objeto de transformación industrial.

Conforme al Diccionario de la Real Academia de la Lengua Española se obtienen las definiciones siguientes:

- Agricultura. - Proviene del latín agricultura, que significa labranza o cultivo de la tierra.

- Ganadería. - Significa conjunto de reses bravas de la misma casta que se conocen con el nombre del propietario, la crianza, granjería o tráfico de ganado.

- Pesqueras. - Proviene del latín piscarius, que significa que pesca. Perteneciente o relativo a la pesca. Industria Pesquera. Barco Pesquero. Sitio o lugar donde frecuentemente se pesca.

- Silvícolas. - El que habita en la selva.

\section{Deducción de Gastos e Inversiones.}

En el artículo 74 de la L.I.S.R. indica que se debe acatar la obligaciones del Título IV, Capitulo II, Sección I, el cual en su artículo 103 enlista varias deducciones autorizadas, entre otras, la deducción de gastos e inversiones, las cuales en el mismo señala que los gastos e inversiones se consideraran no deducibles, en los términos del artículo 28; referente a gastos no deducibles y en su fracción II limita a los gastos e inversiones en proporción que representen los ingresos exentos respecto del total de ingresos del contribuyente. Lo cual desprende una serie de consideraciones que se deben tomar en cuenta para poder acatar lo predicho por dichos artículos. Primeramente, se tiene que determinar los ingresos gravados y los ingresos exentos, seguido del cálculo de la proporción para determinar los gastos e 
Año 13.

Revista de Investigación

Núm. 33

Académica sin Frontera

ISSN: 2007-8870

\section{http://revistainvestigacionacademicasinfrontera.com}

Recibido el 30 de octubre de 2020. Dictaminado mediante arbitraje favorablemente 10 de diciembre de 2020.

inversiones no deducibles y por ultimo determinar los gastos deducibles, lo cual se ejemplifica a continuación:

Cuadro 1. Determinación de ingresos gravados y exentos

\begin{tabular}{|l|l|}
\hline Ingresos gravados & $\$ 1^{\prime} 128,115.20$ \\
\hline Más: Ingresos exentos & $\$ 523,615.10$ \\
\hline Igual a Ingresos Totales & $\$ 1^{\prime} 651,730.30$ \\
\hline
\end{tabular}

Fuente Elaboración propia

Formula: Proporción no deducible de gastos e inversiones $=$ Ingresos exentos entre el total de ingresos.

Proporción $=\$ 523,615.10 / \$ 1^{\prime} 651,730.30=32 \%$

Si los gastos e inversiones son por un total de $\$ 991,038.18$ los gastos no deducibles se determinan multiplicando los gastos e Inversiones por la proporción, quedando el cálculo de la manera siguiente $\$ 991,038.18 \times 32 \%=\$ 317,132.22$ de gastos e inversiones no deducibles.

Originado de lo anterior también repercutiría en el Impuesto al Valor agregado ya que el proveniente de dichos gastos no deducibles el I.V.A pagado por dichas operaciones, no podría acreditarse y por lo tanto es Imposible pedir su devolución.

En este caso el I.V.A de dichas operaciones es la multiplicación de los gastos e inversiones no deducibles por la tasa a la que haya adquirido o efectuado las operaciones, en este supuesto las operaciones fueron grabadas a la tasa del $16 \%$ por lo tanto el I.V.A no acreditable es por el importe de \$ 50,741.15. 
Año 13.

Núm. 33
Revista de Investigación Académica sin Frontera ISSN: 2007-8870

\section{http://revistainvestigacionacademicasinfrontera.com}

Recibido el 30 de octubre de 2020. Dictaminado mediante arbitraje favorablemente 10 de diciembre de 2020.

Soportando los efectos del artículo 28 fracción II previamente mencionados, se presenta las opiniones de varios Autores en lo referente al tema de estudio. Primeramente, en el libro “Actividades Agropecuarias 2019” de L.C. Antonio Luna Guerra, presenta el ejemplo siguiente:

Si una persona moral tiene un total de ingresos en el año de $\$ 10,000,000.00$ y si son 2 socios, entonces la proporción que representan los ingresos exentos es la siguiente:

Cuadro 2. Porcentaje de Reducción sobre Gastos e Inversiones, Deducciones.

\begin{tabular}{|l|l|}
\hline Concepto & Importe \\
\hline Disminución a los ingresos totales & $\$ 1^{\prime} 176,760.00$ \\
\hline Entre: & \\
\hline Ingresos totales & $10^{\prime} 000,000.00$ \\
\hline Proporción de disminución de los ingresos & 0.1176 \\
\hline PORCENTAJE & $11.76 \%$ \\
\hline
\end{tabular}

Sus deducciones se integran de la siguiente forma:

Cuadro 3. Integración de deducciones

\begin{tabular}{|l|l|}
\hline Concepto & Importe \\
\hline Gastos & $\$ 2^{\prime} 000,000.00$ \\
\hline Más: & \\
\hline Inversiones & $2^{\prime} 000,000.00$ \\
\hline más: & \\
\hline
\end{tabular}


Año 13.

Revista de Investigación

Núm. 33

Académica sin Frontera

ISSN: 2007-8870

\section{http://revistainvestigacionacademicasinfrontera.com}

Recibido el 30 de octubre de 2020. Dictaminado mediante arbitraje favorablemente 10 de diciembre de 2020.

\begin{tabular}{|l|l|}
\hline $\begin{array}{l}\text { Adquisiciones de materia prima, productos terminados o } \\
\text { semiterminados (compras) }\end{array}$ & $2^{\prime} 000,000.00$ \\
\hline SUMA DEDUCCIONES & $\$ 6^{\prime} 000,000.00$ \\
\hline
\end{tabular}

Fuente Elaboración propia

Con base en lo anterior, las deducciones autorizadas no serán de $\$ 6^{\prime} 000,000.00$, sino de $\$ 5^{\prime} 529,600.00$ que son los $\$ 2^{\prime} 000,000.00$ más $\left(\$ 4^{\prime} 000,000.00\right.$ menos $\left.\$ 470,400.00\right)$.

El ejemplo anterior es considerando los ingresos de una persona moral y la disminución de sus ingresos, pero al reducir sus ingresos, también reducen sus deducciones, dando con esto una nueva base del impuesto sobre la renta, llevando a cabo el mismo efecto en todos los tipos de personas morales del sector agropecuario, y en el caso de las personas físicas es lo mismo, pero sólo sobre 40 UMA.

Continuando con el soporte de las limitantes de la fracción II del artículo 28, se presenta un párrafo describiendo la opinión del C.P.C. José Luis Gallegos Barraza (2015), el cual describe de forma breve, dichas limitantes apegado a las reglas 3.8.1, 3.8.2, 3.8.3 y 3.8.4 para 2015 de la resolución Miscelánea fiscal de la forma siguiente:

Una parte de las formulas señala lo siguiente: [DAIPA*(1-IEPA/IT)]. Con la aplicación de esta parte de las formulas se están limitando o disminuyendo la totalidad de las deducciones en la proporción que representen los ingresos exentos respecto del total de ingresos del contribuyente, y no solo las deducciones correspondientes a gastos e inversiones; las únicas deducciones que legalmente están limitadas son las de gastos e inversiones. Lo anterior, de conformidad a lo dispuesto en el artículo 28, fracción II de la LISR.

Se concluye, después de citar varios autores y de la interpretación del artículo 28 fracción II del Impuestos Sobre la Renta, que los ingresos y las deducciones de este sector se 
Año 13.

Revista de Investigación

Núm. 33

Académica sin Frontera

ISSN: 2007-8870

\section{http://revistainvestigacionacademicasinfrontera.com}

Recibido el 30 de octubre de 2020. Dictaminado mediante arbitraje favorablemente 10 de diciembre de 2020.

limitan, según la proporción de los ingresos exentos respecto del total de ingresos; emanando un porcentaje, el cual se multiplica por el total de gastos e inversiones, generando gastos e inversiones no deducibles y derivando un Impuesto al Valor Agregado no deducible y por lo tanto no acreditable.

\section{Resultados}

Después de realizar la presente investigación y de elaborar los casos prácticos de personas físicas y morales del sector primario, se presenta el cuadro número 11 con nombre resultados de Casos prácticos, en el cual se expone un resumen en el cual se compara el I.S.R. determinado aplicando la exención y reducción del Art. 74 L.I.S.R. contra el I.S.R. determinado sin aplicar la exención, solo la reducción; Por otro lado, se presenta los gastos e inversiones no deducibles provocado por la aplicación de la limitante del art. 28 fracción II de L.I.S.R. Asimismo, se determina el I.V.A. no deducible, no acreditable proveniente de los gastos e Inversiones no deducibles. Para finalizar se compara el ahorro en I.S.R. por la aplicación de la exención contra el I.V.A. no deducible, no acreditable generado por su aplicación.

Con la finalidad de comprender mejor los resultados de los casos prácticos, se presenta el cuadro siguiente, el cual refleja que en personas morales da un resultado negativo y en personas físicas un resultado positivo no tan representativo, pero necesario para tomar una buena decisión de aplicación de conveniencia fiscal. 
Año 13.

Revista de Investigación

Núm. 33

Académica sin Frontera

ISSN: 2007-8870

\section{http://revistainvestigacionacademicasinfrontera.com}

Recibido el 30 de octubre de 2020. Dictaminado mediante arbitraje favorablemente 10 de diciembre de 2020.

Cuadro 11. Resultados Casos Prácticos.

\begin{tabular}{|c|c|c|c|c|c|c|}
\hline $\begin{array}{l}\text { Caso } \\
\text { practico }\end{array}$ & $\begin{array}{l}\text { I.S.R. Apl. } \\
\text { Ex. y Red. }\end{array}$ & $\begin{array}{l}\text { I.S.R. sin } \\
\text { Exención }\end{array}$ & $\begin{array}{l}\text { Ahorro en } \\
\text { I.S.R. }\end{array}$ & $\begin{array}{l}\text { Gastos } \\
\text { Inv. N.D. }\end{array}$ & $\begin{array}{l}\text { I.V.A N.D., } \\
\text { N.A. }\end{array}$ & $\begin{array}{ll}\text { Pérdida } & \\
\text { Ahorro. } & \end{array}$ \\
\hline $\begin{array}{l}\text { \#1 P.M. Forma } \\
\text { General }\end{array}$ & $\$ 231,783.47$ & $\$ 774,086.06$ & $\$ 542,302.59$ & $\$ 3^{\prime} 759,846.64$ & $\$ 601^{\prime} 575.46$ & $\$-59,272.87$ \\
\hline $\begin{array}{l}\text { \#2 } \text { P.M. ING. } \\
\text { Sup.423 UMA }\end{array}$ & $\$ 974,161.09$ & $\$ 1^{\prime} 501,684.93$ & $\$ 527,523.84$ & $\$ 3^{\prime} 776,513.32$ & $\$ 604,242.13$ & $\$-76,718.29$ \\
\hline $\begin{array}{lrr}\# 3 \quad \text { P.M. } & \text { Ing. } \\
\text { Menor } & 423 \\
\text { UMA } & \\
\end{array}$ & $\$ 231,783.46$ & $\$ 774,086.07$ & $\$ 542,302.61$ & $\$ 3^{\prime} 759,846.64$ & $\$ 601,575.46$ & $\$-59,272.85$ \\
\hline $\begin{array}{l}\text { \#4 P.F. Forma } \\
\text { General }\end{array}$ & $\$ 593,169.26$ & $\$ 708,596.55$ & $\$ 115,427.29$ & $\$ 718,794.21$ & $\$ 115,007.07$ & $\$ 420.22$ \\
\hline $\begin{array}{lrr}\# 5 & \text { P.F. } & \text { Ing. } \\
\text { Sup. } & 423 & \text { UMA }\end{array}$ & $\$ 1^{\prime} 409,093.94$ & $\$ 1^{\prime} 531,580.63$ & $\$ 122,486.69$ & $\$ 666,443.52$ & $\$ 106,630.96$ & $\$ 15,855.73$ \\
\hline $\begin{array}{lrr}\# 6 & \text { P.F. } & \text { Ing. } \\
\text { Menor } & 423 \\
\text { UMA } & \\
\end{array}$ & $\$ 593,169.25$ & $\$ 708,596.55$ & $\$ 115,427.30$ & $\$ 718,794.21$ & $\$ 115,007.07$ & $\$ 420.23$ \\
\hline $\begin{array}{l}\# 7 \quad \text { PM ING. } \\
\text { Sup. } 423 \text { UMA } \\
\text { Sin aplicar EX. }\end{array}$ & $\$ 974,161.09$ & $\$ 1{ }^{\prime} 501,684.93$ & $\$ 527,523.84$ & $\$ 3^{\prime} 776,513.32$ & $\$ 604,242.13$ & $\$ 76,718.29$ \\
\hline
\end{tabular}

Fuente Elaboración propia

Los casos prácticos 2 y 7 se aplicó a una persona moral que rebasa ingresos por 423 UMA con Ingresos totales de \$18’512,320.20 emitiendo los resultados siguientes. Un I.S.R. a cargo aplicando exención de \$974,161.09, a cargo sin aplicar exención de \$1’501,684.93, obteniendo un remanente de $\$ 527,523.84$ y un I.V.A. no deducible, no acreditable por aplicar exención de \$604,242.13.

Por lo que se concluye que el contribuyente refleja un resultado negativo al aplicar la exención, ya que, si bien es cierto que aplicando la exención y la reducción se distingue una disminución del I.S.R por \$ 527,523.84 la perdida en el I.V.A. acreditable proveniente de los 
Año 13.

Núm. 33

Académica sin Frontera

ISSN: 2007-8870

\section{http://revistainvestigacionacademicasinfrontera.com}

Recibido el 30 de octubre de 2020. Dictaminado mediante arbitraje favorablemente 10 de diciembre de 2020.

gastos e inversiones no deducibles por la aplicación del artículo 28 fracción II es superior por $\$ 76,718.29$.

\section{Conclusiones}

El régimen de actividades agropecuarias, ganaderas, silvícolas y pesqueras, es un régimen con bastos beneficios contributivos como exenciones, reducciones, estímulos fiscales.

Es necesario conocer de forma amplia y evaluar las repercusiones fiscales que emanen de dichas aplicaciones, como por ejemplo el caso de estudio presentado sobre el análisis de las implicaciones fiscales de la fracción II del artículo 28 de la L.I.S.R. en lo relativo a la deducción de gastos e inversiones para sector primario, ya que dicha aplicación no es del todo benéfica.

Por lo tanto, al aplicar la exención de I.S.R. sobre ingresos gravados para personas morales, emana un resultado negativo en su aplicación; ya que, el ahorro en el Impuesto Sobre la Renta es menor que el efecto negativo sobre la limitación de gastos e inversiones. Obteniendo como consecuencia la limitación de deducciones autorizadas y generando un I.V.A no deducible y por lo tanto no acreditable. Por otro lado, las personas físicas obtienen resultados positivos en su aplicación. Por lo cual se recomienda ampliamente, antes de aplicar un beneficio fiscal, evaluar los beneficios y las repercusiones que se pueden llegar a generar después de su aplicación.

Se recomienda conocer y evaluar cada uno de los beneficios fiscales tales como las facilidades administrativas publicadas por el Servicio de Administración Tributaria. Como, por ejemplo, las facilidades de comprobación consistente en no comprobar los gastos por 


\section{http://revistainvestigacionacademicasinfrontera.com}

Recibido el 30 de octubre de 2020. Dictaminado mediante arbitraje favorablemente 10 de diciembre de 2020.

concepto de mano de obra, alimentación de ganado y gastos menores conforme a los requisitos establecidos en la L.I.S.R. si no solo cumpliendo con los previstos en dicha facilidad. Por otro lado, existe la facilidad de presentar pagos provisionales semestrales, lo cual tiene un efecto positivo en la economía del sector, porque no realizan un pago provisional cada mes. Seguido de la facilidad de la no obligación de emisión de cheques nominativos, siempre que su monto no supere del Importe de $\$ 5,000.00$ y sea a una misma persona en el mismo mes de que se trate.

\section{Referencias}

Barraza, J.L. (2016). Reducción del ISR para contribuyentes dedicados a realizar actividades del sector primario.

Recuperado de: http://imcp.org.mx/wp-content/uploads/2015/02/Fiscoactualidadesfebrero_n $\tilde{A}^{\circ} \mathrm{m}-04 . p d f$

Congreso de los Estados Unidos Mexicanos. (2019). Ley del Impuesto Sobre la Renta. Recuperado de:

https://www.sat.gob.mx/normatividad/18912/leyes -fiscales

Congreso de los Estados Unidos Mexicanos. (2019). Ley del Impuesto al Valor Agregado. (2019).

Recuperado de:

https://www.sat.gob.mx/normatividad/18912/leyes-fiscales

Congreso de los Estados Unidos Mexicanos. (2020). Ley de Ingresos de la Federación.

Recuperado de:

http://www.diputados.gob.mx/LeyesBiblio/pdf/LIF_2020_251119.pdf

Congreso de los Estados Unidos Mexicanos. (2019). Código Fiscal de la Federación.

Recuperado de: https://www.sat.gob.mx/normatividad/18912/leyes -fiscales

Consejo Mexicano de Normas de Información Financiera, A. C. (CINIF). (2020). Normas de Información Financiera.

Recuperado de: https://www.cinif.org.mx/uploads/AuscultacionMejoras2020.pdf 
Año 13.

Revista de Investigación

Núm. 33

Académica sin Frontera

ISSN: 2007-8870

\section{http://revistainvestigacionacademicasinfrontera.com}

Recibido el 30 de octubre de 2020. Dictaminado mediante arbitraje favorablemente 10 de diciembre de 2020.

Contadormx. (2016). Tratamiento Fiscal para los AGAPES-Facilidades, Obligaciones, y Pagos Provisionales.

Recuperado de:

https://contadormx.com/2016/06/13/tratamiento-fiscal-para-los-agapes-facilidadesobligaciones-y-pagos-provisionales/

Estrada, H. (2015). Elementos Esenciales de los Impuestos.

Recuperado de:

http://tareasjuridicas.com/2015/10/01/elementos-esenciales-de-los-impuestos/

García Sánchez, I.M. (2009). Introducción a la Contabilidad.

Recuperado de:

https://eumed.net/libros-gratis/2009c/576/index.htm

Luna Guerra, A. (2019). Actividades Agropecuarias 2019. Ciudad de México. Ediciones

Fiscales ISEF, S.A.

Magallón, I. (2014). Ingresos Exentos para el Sector Primario.

Recuperado de: http://www.kimquezada.com/blog/2014-19/

Pérez Chávez, F.O. (2012). Sector Primario Régimen Fiscal Agricultura, Ganadería, Silvicultura y Pesca. México DF. Tax Editores Unidos, S.A. de C.V.

Pina García, J.P. (1993). Diccionario de Derecho. México. Editorial Porrúa, S.A.

Procuraduría de la Defensa del Contribuyente. (2015). Lo que todo contribuyente debe saber.

Recuperado de:

https://www.gob.mx/prodecon/documentos/lo-que-todo-contribuyente-debe-saber

Real Academia Española. (2014). Diccionario.

Recuperado de:

https://www.rae.es/diccionario-de-la-lengua-espanola/el-diccionario-en-el-brae

Servicio de Administración Tributaria. (2020). Facilidades Administrativas.

Recuperado del Diario Oficial de la Federación:

http://www.dof.gob.mx/nota_detalle.php?codigo=5586697\&fecha=18/02/2020

Secretaria de Hacienda y Crédito Público. (2020).Resolución Miscelánea Fiscal.

Recuperado de: https://www.sat.gob.mx/normatividad/21127/resolucion-

miscelanea-fiscal-(rmf)-

Secretaria de Hacienda y Crédito Público. (1989). ACUERDO que establece por el ejercicio

fiscal 1989 mediante reglas generales, bases especiales de tributación en materia de 
Año 13.

Revista de Investigación

Núm. 33

Académica sin Frontera

ISSN: 2007-8870

\section{http://revistainvestigacionacademicasinfrontera.com}

Recibido el 30 de octubre de 2020. Dictaminado mediante arbitraje favorablemente 10 de diciembre de 2020.

los impuestos federales que se indican, a los contribuyentes personas físicas pequeñas o medianas empresas dedicados a las actividades agrícolas en los estados de Baja California, Baja California Sur, Sinaloa y Sonora.

Recuperado de Diario Oficial de la Federación:

http://dof.gob.mx/nota_to_imagen_fs.php?codnota=4832007\&fecha=18/10/1989\&c $\underline{\text { od_diario }=207983}$

Suprema Corte de Justicia. (2007). RENTA. QUÉ DEBE ENTENDERSE POR "INGRESO" PARA EFECTOS DEL TÍTULO II DE LA LEY DEL IMPUESTO RELATIVO.

Recuperado de: https://suprema-corte.vlex.com.mx/vid/jurisprudencial-primera-salaaislada-27176317

Suprema Corte de Justicia. (2015). IMPUESTOS, ELEMENTOS ESENCIALES DE LOS. DEBEN ESTAR CONSIGNADOS EXPRESAMENTE EN LA LEY.

Recuperado de: http://tareasjuridicas.com/2015/10/01/elementos-esenciales-de-losimpuestos/

UNICEF. (2010) Sector primario.

Recuperado de:

https://www.unicef.org/ecuador/LIBRO_DE_EL_ORO_Parte2.dp

Venustiano Carranza. (2020). Constitución Política de los Estados Unidos Mexicanos.

Recuperado de:

https://www.sat.gob.mx/normatividad/18912/leyes -fiscales 
"Fl whiser ite mis hijos

Año 13.

Núm. 33
Revista de Investigación

Académica sin Frontera

ISSN: 2007-8870

http://revistainvestigacionacademicasinfrontera.com

Recibido el 30 de octubre de 2020. Dictaminado mediante arbitraje favorablemente 10 de diciembre de 2020.

\section{Directorio Institucional}

Dr. Enrique Fernando Velázquez Contreras

Rector

Dr. Ramón Enrique Robles Zepeda

Secretario General Académico

Dra. Rosa María Montesinos Cisneros

Secretaria General Administrativa

Dr. Rodolfo Basurto Álvarez

Director de Vinculación y Difusión

Dra. Adriana Leticia Navarro Verdugo

Vicerrectora de la Unidad Regional Sur

Dr. Ernesto Clark Valenzuela

Director de la División de Ciencias Económicas y Sociales

Dr. Francisco Espinoza Morales

Secretario de la División de Ciencias Económico y Sociales

Dra. Leticia María González Velásquez

Jefe del Departamento de Ciencias Económico Administrativas

Dra. Lidia Amalia Zallas Esquer

Jefe de Departamento de Ciencias Sociales 
Año 13.

Revista de Investigación

Núm. 33

Académica sin Frontera

ISSN: 2007-8870

http://revistainvestigacionacademicasinfrontera.com

Recibido el 30 de octubre de 2020. Dictaminado mediante arbitraje favorablemente 10 de diciembre de 2020.

\section{Comité Directivo}

\section{Editor Responsable}

Dr. Francisco Espinoza Morales

\section{Directora}

Dra. Leticia María González Velásquez

\section{Subdirector}

Dr. Javier Carreón Guillen

\section{Editor Científico}

Dr. Cruz García Lirios

Master Gráfico

M.T.I. Francisco Alan Espinoza Zallas

Nos complace anunciar que su diario, "Academic Research Journal Withoutborders" (ISSN/EISSN 2007-8870) fue evaluado positivamente en la indexación Citefactor, ahora la página de la revista está disponible en línea, en caso de cualquier problema.

Journals Master | International Innovative Journal Impact Factor (IIJIF)

Red Latinoamericana de revistas Académicas en Ciencias Sociales y Humanidades
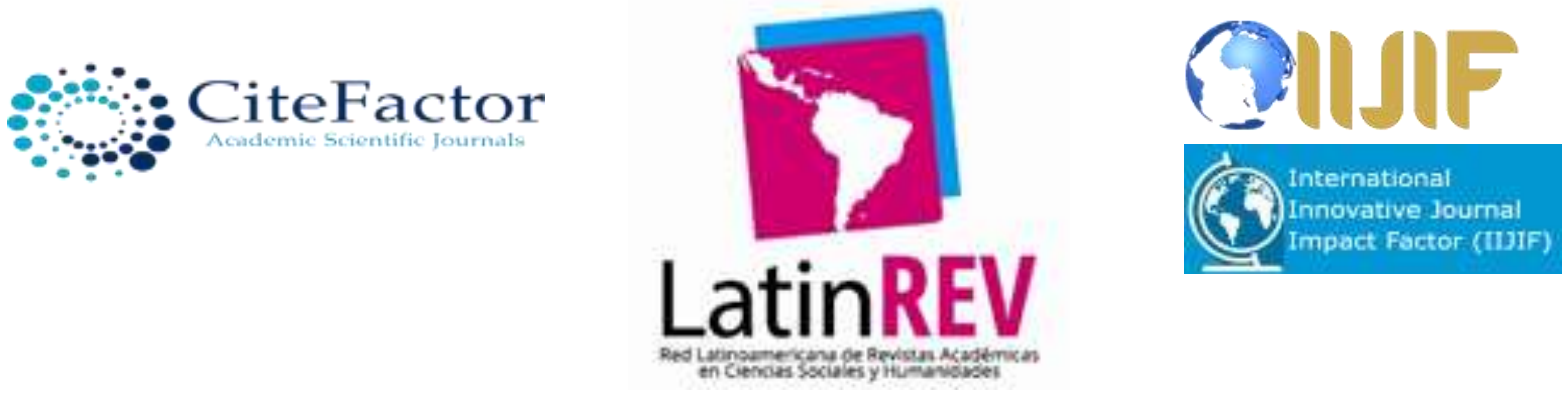
Año 13.

Revista de Investigación

Núm. 33

Académica sin Frontera

ISSN: 2007-8870

http://revistainvestigacionacademicasinfrontera.com

Recibido el 30 de octubre de 2020. Dictaminado mediante arbitraje favorablemente 10 de diciembre de 2020.

\section{Comité editorial}

Dra. Angélica María Rascón Larios

Universidad de Sonora. México

Dra. María del Rosario Molina González

Universidad de Sonora

Dra. Francisca Elena Rochin Wong

Universidad de Sonora. México

Dra. Lidia Amalia Zallas Esquer

Universidad de Sonora. México

Dra. Beatriz Llamas Arechiga

Universidad de Sonora. México

Dr. Rogelio Barba Álvarez

Universidad de Guadalajara. México

Dra. Rosa María Rincón Ornelas

Universidad de Sonora. México

Dr. Juan Flores Preciado

Universidad de Colima. México

Dr. Amado Olivares Leal. Universidad de Sonora

Universidad de Sonora. México

Dr. Guillermo Velázquez Valadez.

Instituto Politécnico Nacional (IPN) México

Dr. Hugo Nefstalí Padilla Torres.

Universidad Estatal de Sonora. México

Dr. Luis Ramón Moreno Moreno.

Universidad Autónoma de Baja California. México

Dr. Miguel Ángel Vázquez Ruiz.

Universidad de Sonora. México 


\section{http://revistainvestigacionacademicasinfrontera.com}

Recibido el 30 de octubre de 2020. Dictaminado mediante arbitraje favorablemente 10 de diciembre de 2020.

Dra. Lorena Vélez García.

Universidad Autónoma de Baja California. México

Dra. Pabla Peralta Miranda.

Universidad Simón Bolívar, Barranquilla, Colombia

Mtro. Roberto Espíritu Olmos

Universidad de Colima (FCA Tecomán) Colima

Dr. Héctor Priego Huertas.

Universidad de Colima (FCA Tecomán) Colima

Mtra. María Guadalupe Alvarado Ibarra.

Universidad de Sonora. México.

MSc. Celso Germán Sánchez Zayas

Universidad de Camagüey, Ignacio Agramonte Loynaz, Cuba

Dra. María Luisa Quintero Soto

Universidad Autónoma del Estado de México

Dr. Eyder Bolivar Mojica

Universidad Católica, Luis Amigó, Medellin, Colombia

Revisores de Textos en Inglés

Mtro. Renato Encinas

Mtra. Cecilia Guadalupe Martínez Solano

\section{Comité científico}

Dr. Rosendo Martínez Jiménez. Universidad Autónoma Benito Juárez de Oaxaca.

Dr. Hugo Neftalí Padilla. Universidad Estatal de Sonora

Dra. María Teresa Gaxiola Sánchez. Universidad de Sonora.

Dr. José Cesar Kaplan. Universidad Estatal de Sonora.

Dr. Alfredo Islas Rodríguez. Universidad de Sonora

Frecuencia de publicación: semestral / 2 números por año. 


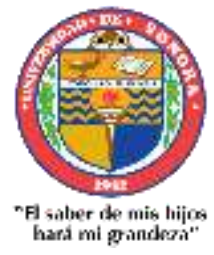

Año 13.

Núm. 33
( Julio - Diciembre 2020)

Revista de Investigación Académica sin Frontera

ISSN: 2007-8870

http://revistainvestigacionacademicasinfrontera.com

Recibido el 30 de octubre de 2020. Dictaminado mediante arbitraje favorablemente 10 de diciembre de 2020.

Revista de Investigación Académica sin Frontera (RIASF) con (ISSN: 2007-8870) es un interlocutor internacional de acceso abierto revisado diario en línea en el ámbito del de las Ciencias Económicas Administrativas y Sociales. Su objetivo principal es dar a los trabajos de investigación de calidad. Cubre todas las sub-campos de los campos anteriormente mencionados. Proporciona la plataforma a académicos, estudiantes y profesionales. Sólo pública trabajos de investigación y artículos de revisión inicial. Documento presentado debe cumplir con algunos criterios como, debe ser original, inédita y no estén sometidos a ninguna otra revista.

RIASF es una revista arbitrada / Revisión por pares International. Publicamos documentos sobre una variedad de temas, contextos y estrategias de análisis que examinan la relación entre la rápida evolución para la Sociedad y la tecnología del conocimiento.

REVISTA DE INVESTIGACIÓN ACADÉMICA SIN FRONTERA, Año 13, No. 33, Julio - diciembre 2020, es una publicación semestral de investigación científica, editada por la Universidad de Sonora, a través de las División de Ciencias Económicas y Sociales, de la Unidad Regional Sur, Blvd. Lázaro Cárdenas No. 100, Col. Francisco Villa, Navojoa, Sonora, Sonora, México, C.P. 85880. Tel. (642) 42599-54.

http://www.revistainvestigacionacademicasinfrontera.com/, revistaacademicasinfrontera@unison.mx. Editor responsable: Francisco Espinoza Morales. Reserva de Derechos al Uso Exclusivo: 042013-121811323700-203 e ISSN: 2007-8870, ambos otorgados por el Instituto Nacional de Derecho de Autor. Inscrita en el Directorio de LATINDEX, con Núm. De folio 20014, folio único 14590. Responsable de la última actualización de este Número, Unidad Informática de la Universidad de Sonora, fecha de la última modificación, 30 de diciembre 2020, indexada a Cite Factor Academic Scientific Journal y Journals Master (IIJIF) y Red Latinoamericana de Revistas Académicas en Ciencias Sociales y Humanidades, (Latín Rev). Las opiniones expresadas por los autores no necesariamente reflejan la postura del editor de la publicación. Se autoriza la reproducción total o parcial de los contenidos e imágenes en la presente publicación siempre y cuando se cuente con la autorización del editor y se cite plenamente la fuente. 
Año 13.

Revista de Investigación

Núm. 33

Académica sin Frontera

ISSN: 2007-8870

http://revistainvestigacionacademicasinfrontera.com

Recibido el 30 de octubre de 2020. Dictaminado mediante arbitraje favorablemente 10 de diciembre de 2020.

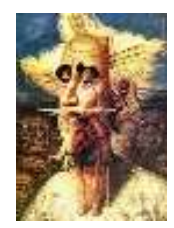

Nos complace anunciar que su diario, "Academic Research Journal Withoutborders" (ISSN/EISSN 2007-8870) fue evaluado positivamente en la indexación Citefactor, ahora la página de la revista está disponible en línea, en caso de cualquier problema.

Journals Master | International Innovative Journal Impact Factor (IIJIF)

\section{Red Latinoamericana de revistas Académicas en Ciencias Sociales y Humanidades}
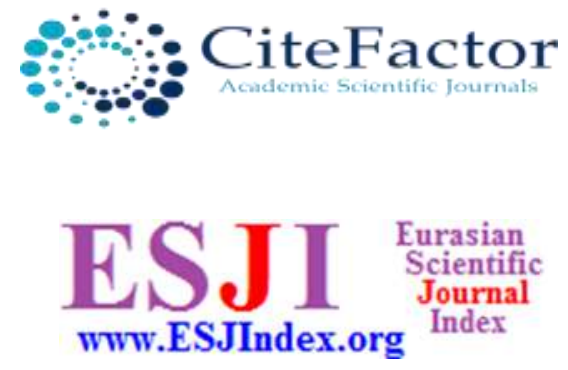

https://www.neliti.com

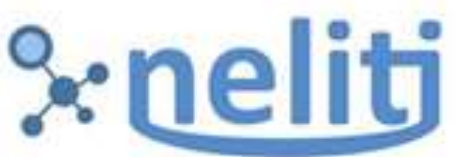

Indonesia's Research Repository

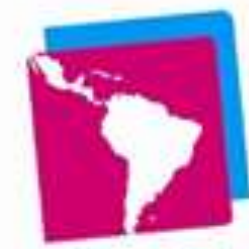

LatinREV
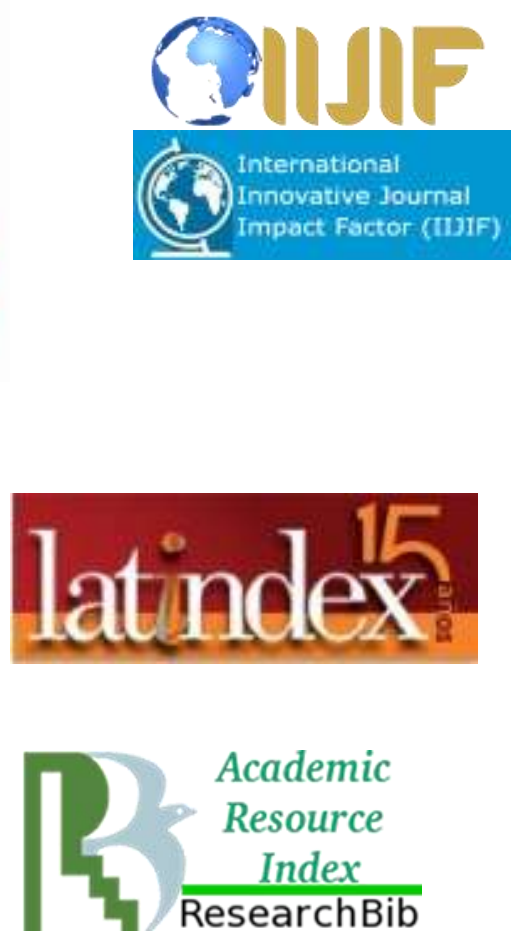